\title{
Downstaging in opportunistic breast cancer screening in Brazil: a temporal trend analysis
}

\author{
Diama Bhadra Vale ${ }^{1 *}$ D, Cassio Cardoso Filho ${ }^{1}$, Julia Yoriko Shinzato ${ }^{1}$, Fernanda Servidoni Spreafico ${ }^{1,2}$, \\ Partha Basu ${ }^{3}$ and Luiz Carlos Zeferino ${ }^{1}$
}

\begin{abstract}
Background: Breast cancer is the most common female cancer in Brazil with an estimated 60 thousand new cases per year. Widespread use of mammography opportunistic screening has been observed in the last 20 years, including women under 50 years old. The present study aimed to analyse the trends in breast cancer stage distribution at diagnosis as a function of age in the study period.

Methods: This paper examined temporal trends of stage distribution in women with breast cancer diagnosed between 2000 and 2015 in São Paulo state, Brazil. Data from the Hospital Cancer Registry of the region were utilized. Completeness was high. The sample was described according to age, stage and date of diagnosis using absolute frequency and proportions (\%). For trends, the Cochran-Armitage test was used with a 5\% level of significance ( $P$-value< 0.05$)$.

Results: A total of 93,674 women were included in the analysis with a median age of 56 years old. One-third (34. $4 \%)$ of the women were younger than 50 years old, and stage II was the most frequent stage (36.4\%), even when analysed by age groups. Stage 0 corresponded to $7.7 \%$ ( 7247 women) of cases. In the study period, there was a significant trend towards an increase in Stages 0, I and IV $(P<0.01)$ and a trend towards a decrease in Stages IIA, IIB and IIIB $(P<0.001)$. Stage IIA was more prevalent until 2009, and stage I was more prevalent thereafter. The trends to increase the proportion of Stages 0 and I and to decrease the proportion of stages IIA, IIB and IIIB were significant in all age groups.

Conclusions: Breast cancer cases are diagnosed mainly at early stages, and approximately one-third of cases are younger than 50 years old. Downstaging has been shown. Opportunistic screening may have supported these results. Further studies are needed to show whether these results will impact the prognosis.
\end{abstract}

Keywords: Breast Neoplasms, Neoplasm Staging, Early Detection of Cancer, Epidemiologic Studies

\section{Background}

Measuring changes in cancer burden is an important parameter to evaluate cancer control programmes. Breast cancer is the most common cancer and the leading cause of cancer death among women worldwide [1]. Screening has contributed significantly to reduce cancer mortality, especially in countries that implemented population-based well-organized screening programmes [2]. An intermediate

\footnotetext{
* Correspondence: dvale@unicamp.br

'Obstetrics and Gynecology Department, School of Medical Sciences of Unicamp, Rua Alexander Fleming 101, Campinas 13083-790, Brazil Full list of author information is available at the end of the article
}

indicator of breast cancer screening effectiveness is the downstaging of the disease in the screened population. Tracking the stage at diagnosis over time can help to understand the impact of screening.

Early detection of breast cancer aims to identify the cancer at an early, often curable stage. Differences in breast cancer survival are observed between stage I and II but are more evident between stages II and III or IV $[3,4]$. Mammography screening is capable of detecting the cancer at a size between 0.2 and $1.0 \mathrm{~cm}$, when the cure rate is as high as that in microinvasive carcinoma $(\leq 0.1 \mathrm{~cm})[5]$. There is sufficient evidence that breast

(c) The Author(s). 2019 Open Access This article is distributed under the terms of the Creative Commons Attribution 4.0 International License (http://creativecommons.org/licenses/by/4.0/), which permits unrestricted use, distribution, and reproduction in any medium, provided you give appropriate credit to the original author(s) and the source, provide a link to the Creative Commons license, and indicate if changes were made. The Creative Commons Public Domain Dedication waiver (http://creativecommons.org/publicdomain/zero/1.0/) applies to the data made available in this article, unless otherwise stated. 
cancer screening in women from 50 to 69 years old reduces mortality rates [2]. The evidence favouring screening of women under 50 years old is considered to be limited [2].

In Brazil, a national guideline recommends to screen women between 50 and 69 years old every two years with mammography [6]. In the absence of a system to identify eligible women individually and invite them to screening, the programme is opportunistic. In São Paulo state, widespread use of mammography screening has been observed in the last 20 years due to incentive policies. In 2000, approximately 441,000 mammograms were performed in the public health system, and the number increased by three-fold to $1,307,000$ mammograms in 2012 [7]. From 2000 to 2015, there was an increase in the female population of the state by $29 \%$ in the $40-49$ age group, $74 \%$ in the $50-59$ age group and $81 \%$ in the $60-69$ age group [8]. Screening under 50 years of age is very common and represents approximately $20 \%$ of all mammograms performed [9]. The estimated incidence rate per 100,000 women in Sao Paulo state was 42 in 2002 and 58 in 2018 regardless of age $[10,11]$. Diagnosis and treatment are usually performed at the cancer centres. Health care in Brazil is free of charge, although approximately $40 \%$ of São Paulo population co-uses private care [12].

The present study aimed to analyse the trends in breast cancer stage distribution at diagnosis as a function of age in São Paulo state during the period when opportunistic screening was highly prevalent. The results can help policy makers monitoring the implementation of cancer control interventions.

\section{Methods}

This was a hospital-based study of temporal trends of stage distribution of the women with breast cancer diagnosed between 2000 and 2015 in São Paulo state, Brazil. The data were accessed online in July 2017 from the Hospital-based cancer registry system (HBCR) managed by the São Paulo Cancer Center Foundation (FOSP) [13].

In the HBCR, the women were anonymized, and a number of variables were available in every case. We selected female cases coded as C-50 (breast cancer) according to the International Classification of Diseases, 10th edition (ICD-10). The variables age, stage and date of diagnosis were selected for analysis. The data in HBCR were provided by trained hospital technicians who regularly review cases from records and enter data into an online platform. All hospitals licensed for cancer care in São Paulo state are required to provide data to the HBCR. To avoid the duplication of cases, we included only analytical cases, i.e., cases from a particular hospital registered for primary treatment. Only cases for which the stage at diagnosis was indicated were included in the main analysis. Completeness was high. Non-staged cases corresponded to $2.3 \%$ of total cases.

Cases were staged and recorded according to the American Joint Committee on Cancer based on the TNM Classification of Malignant Tumours system (TNM). Stage IIIC started to be registered in the HBCR after 2006. To standardize the data, we aggregated cases from stage IIIB and IIIC as stage IIIB.

Variables were described by absolute frequency and proportions (\%). For trends, the Cochran-Armitage test was used with a $5 \%$ level of significance $(P$-value $<0.05)$. A positive $(+)$ statistic test $(Z)$ meant a trend to increase, and a negative $(-)$ test indicated a trend to decrease. SAS System for Windows (Statistical Analysis System), version 9.2 was used to perform the analysis.

The Ethics Committee of the State University of Campinas under the number CAAE 89399018.2.0000.5404 approved this study. The Committee waived the need for consent.

\section{Results}

The total sample included 93,674 women with a median age of 56.15 (SD 13,51) years old. The distribution of the cases by age and stage is reported in Table 1. Most women were between 50 to 59 years old. Approximately one-third (32,254 women or $34.4 \%)$ were younger than 50 years old. Stage IIA was the most prevalent Stage in all age groups. Stage 0 was less prevalent in women under 40 or older than 69 years old.

During the study period, there was significant trend towards an increase in Stages 0, I and IV $(P<0.01)$ and a trend towards a decrease in Stages IIA, IIB and IIIB $(P<0.001)$ (Fig. 1). Stage IIA was more prevalent until 2009 , and Stage I was more prevalent thereafter.

Figure 2 shows the trends of the proportion of cases by stage as a function of age group. The trend to increase the proportion of Stages 0 and I was statistically significant in all age groups. The trend to decrease the proportion of stages IIA, IIB and IIIB was also significant in all age groups. There was a statistically significant trend to increase stage IV in the 50-59 years old age group.

\section{Discussion}

From 2000 to 2015, the majority of the breast cancer cases were diagnosed at localized stages in São Paulo, Brazil. We observed a reduction in the proportion of cases diagnosed at a late stage in the period. There was also a trend showing an increase in stage 0 in all age groups. These results occur simultaneously with the widespread use of opportunistic mammography screening in the region [7]. However, the impact of the large volume of screening and the change in the stage 
Table 1 Distribution of breast cancer cases in women as a function of age and stage at diagnosis from 2000 to 2015 in São Paulo/ Brazil

\begin{tabular}{|c|c|c|c|c|c|c|}
\hline \multirow{2}{*}{$\begin{array}{l}\text { Group } \\
\text { Age } \\
\text { /Stage }\end{array}$} & $\begin{array}{l}<40 \\
\text { years }\end{array}$ & 40-49 years & 50-59 years & 60-69 years & $\begin{array}{l}\geq 70 \\
\text { years }\end{array}$ & Total \\
\hline & n (\%) & n (\%) & n (\%) & n (\%) & $\mathrm{n}(\%)$ & $\mathrm{n}(\%)$ \\
\hline \multirow[t]{2}{*}{ Stage 0} & 477 & 2095 & 2183 & 1559 & 933 & 7247 \\
\hline & (5.0) & $(9.2)$ & $(8.7)$ & (8.0) & (5.6) & $(7.7)$ \\
\hline \multirow[t]{2}{*}{ Stage I } & 1297 & 4384 & 5642 & 4909 & 3715 & 19,947 \\
\hline & (13.6) & (19.3) & $(22.5)$ & $(25.0)$ & $(22.2)$ & $(21.3)$ \\
\hline \multirow[t]{2}{*}{ Stage IIA } & 2008 & 5065 & 5638 & 4651 & 3960 & 21,322 \\
\hline & $(21.0)$ & $(22.3)$ & $(22.5)$ & $(23.7)$ & $(23.7)$ & (22.8) \\
\hline \multirow[t]{2}{*}{ Stage IIB } & 1594 & 3336 & 3346 & 2336 & 2110 & 12,722 \\
\hline & $(16.7)$ & $(14.7)$ & (13.3) & (11.9) & $(12.6)$ & (13.6) \\
\hline \multirow[t]{2}{*}{ Stage IIIA } & 1757 & 3241 & 2998 & 1935 & 1332 & 11,263 \\
\hline & (18.4) & (14.3) & (12.0) & (9.9) & (8.0) & (12.0) \\
\hline \multirow[t]{2}{*}{ Stage IIIB } & 1419 & 2878 & 3227 & 2530 & 2914 & 12,968 \\
\hline & (14.9) & (12.7) & $(12.9)$ & (12.9) & $(17.4)$ & (13.8) \\
\hline \multirow[t]{2}{*}{ Stage IV } & 994 & 1709 & 2057 & 1687 & 1758 & 8205 \\
\hline & (10.4) & (7.5) & (8.2) & (8.6) & $(10.5)$ & (8.8) \\
\hline \multirow[t]{2}{*}{ Total } & 9546 & 22,708 & 25,091 & 19,607 & 16,722 & 93,674 \\
\hline & (100.0) & (100.0) & (100.0) & (100.0) & (100.0) & (100.0) \\
\hline
\end{tabular}

distribution on the reduction of breast cancer mortality over time needs to be studied further $[14,15]$.

The World Health Organization (WHO) has recommended mammography as the exclusive screening modality in the countries with adequate resources to implement such a programme with appropriate quality assurance. Early diagnosis of symptomatic women is a strategy, particularly in low- and middle-income countries where the disease is diagnosed in late stages and resources are very limited [16]. An increase in the proportion of breast cancers detected at an early stage is commonly referred to as downstaging [17]. In our study, $64,7 \%$ of the women were diagnosed at early stages (stages I or II). This finding is similar to that observed in high-income countries and other countries from Latin America [18-21]. However, the stage shift may be the consequence of large-scale screening mammography and/or better access to care.

The significant increase in the proportion of carcinoma in situ (CIS) consistently observed across the age groups is most likely due to mammography screening. It is also important to monitor the proportion of CIS among the total breast cancers detected. The European Breast Cancer Screening Guidelines recommend that the proportion should not exceed 15\% [22]. In Brazil, the proportion of CIS remains below this level. Mammography screening

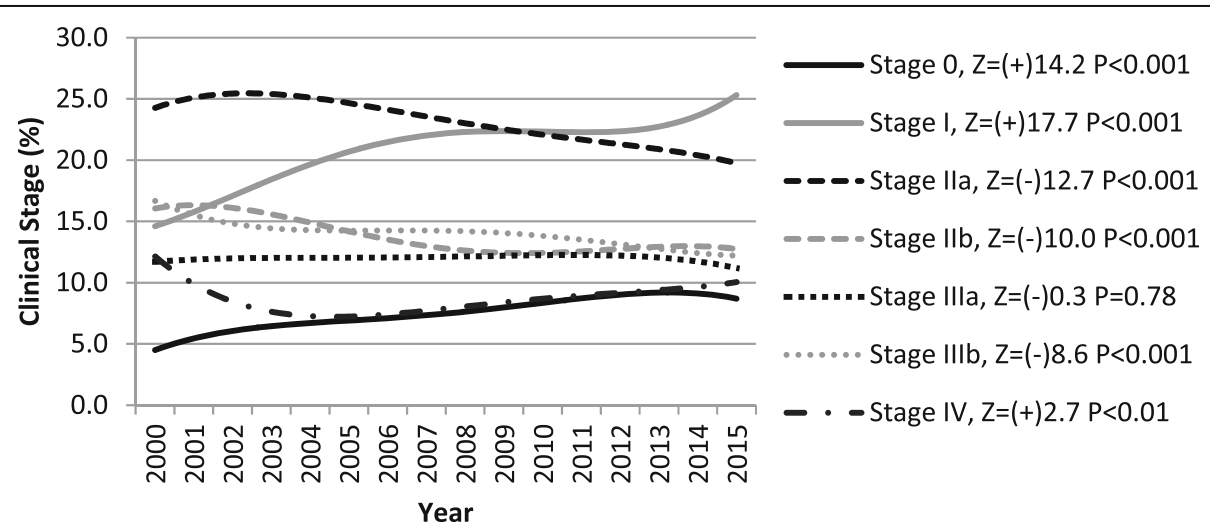

Fig. 1 Time trends of the proportion of breast cancer stage from 2000 to 2015, São Paulo/Brazil. Legend: Z - Cochran-Armitage test for trend; (+) trend to increase; $(-)$ trend to decrease. $P=P$-value 


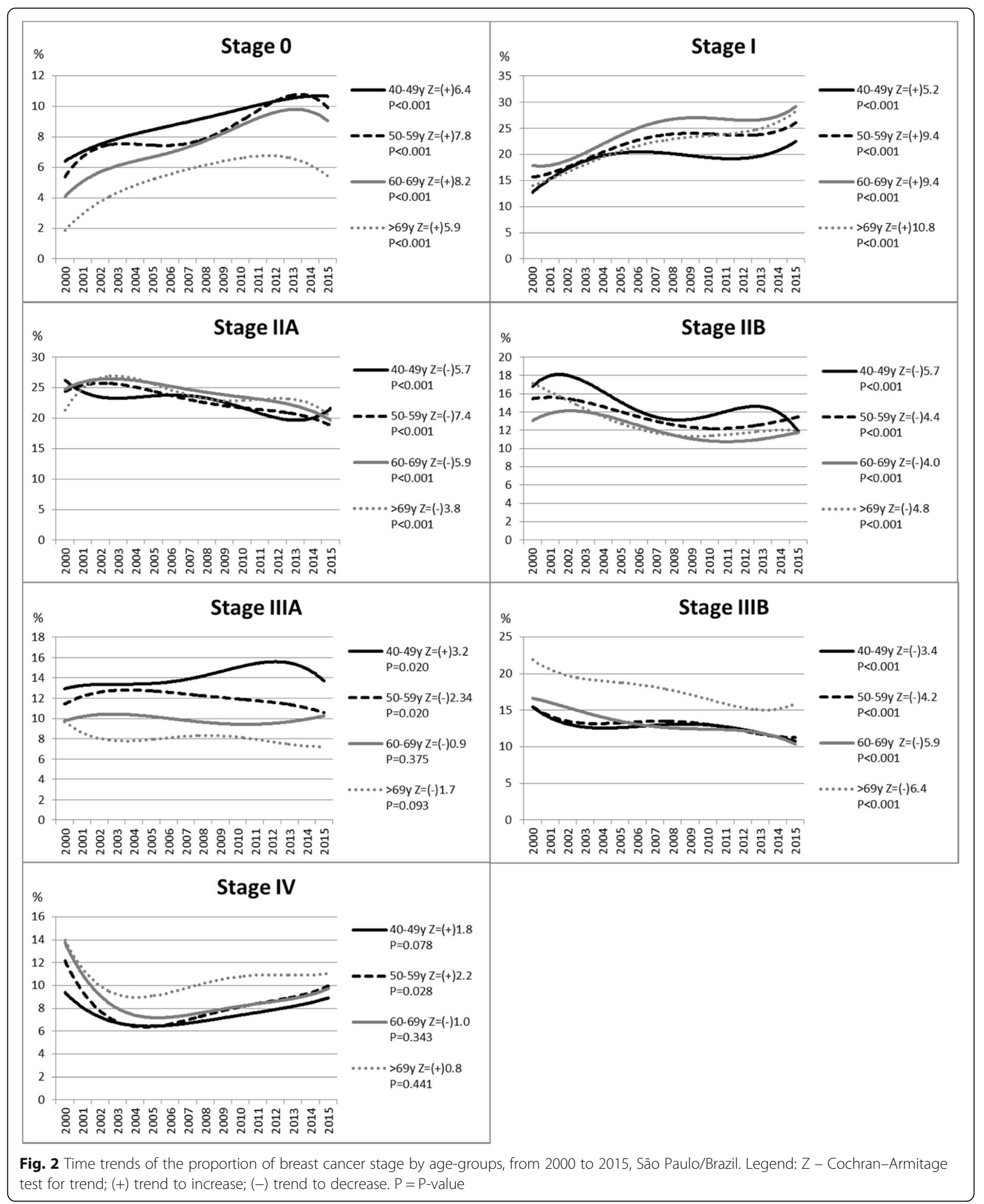


has the inherent risk of 'overdiagnosis' due to the detection of early breast cancers that would not have caused any symptoms during the lifetime of the women through screening. The Independent United Kingdom Panel on Breast Cancer Screening estimates that for every 10,000 women in the United Kingdom aged 50 years attending screening for the next 20 years, 129 breast cancers would be over-diagnosed; however, screening would prevent 43 deaths from breast cancer [23].

In Brazil, screening is opportunistic due to the lack of an invitation system and a weak organization infrastructure. Most of the evidence about the effectiveness of mammography screening on the reduction of breast cancer mortality comes from population-based organized programmes [24-27]. It is important to convert the current opportunistic programme in Brazil to a population-based organized programme with an effective call-recall system, implement a screening registry and ensure robust quality assurance at all levels. In fact, the European experience has demonstrated that it is much more challenging to convert an opportunistic programme to a population-based programme compared with initiating a new population-based programme [28]. An organized mammography programme will be much more effective, minimize the risk of harm and ensure utilization of resources in a more cost-effective manner.

Approximately one-third (34.4\%) of cases in this study occurred in women younger than 50 years old, which is similar to that was observed in 2000-2013 in the population-based cancer registry of São Paulo city, the capital of the state $(32,9 \%)$ [29]. In the United States of America, only $20.0 \%$ of cases were in this age-group with a median age of approximately 62 years old [30]. The median age is 56.2 years in this study and 55.5 years in Mexico [31].

This difference can be due to the higher proportion of women in the younger age group, a different genetic profile observed in Latin women or an effect of the widespread use of mammography opportunistic screening in women under 50 years in Brazil. Of note, $28.5 \%$ of cancers in women from 40 to 49 years old were diagnosed in stages 0 and $\mathrm{I}$.

Quality of data in low and middle-income countries is low, so it is difficult to establish evidence to better planning cancer control actions. This study was facilitated by the high completeness of data in the hospital based cancer registry of São Paulo, a high-middle income state in Brazil. The registry of more than 90,000 breast cancer cases allowed analysis with statistical significance to be performed. The main limitation is regarding the non-population based nature of the registry, preventing estimation of incidence rates. Population-based cancer registries are not commonly available in the region for analysis of temporal prevention trends. Furthermore, we do not know whether cancers in the registry were detected by screening. The relation of these findings with mammographic screening cited in the discussion is a hypothesis given that screening data are weak. Efforts should be made to improve monitoring of screening.

\section{Conclusions}

During the study period, a clear downstaging of breast cancers could be observed probably due to a substantial increase in the use of (opportunistic) mammography screening. Breast cancer cases were diagnosed mainly at early stages, and approximately one-third of cases were diagnosed in women under 50 years old. We expect that these results will support further actions from the Ministry of Health to improve the quality and organization of the programme.

\section{Abbreviations \\ CIS: Carcinoma in situ; FOSP: São Paulo Cancer Center Foundation: HBCR: Hospital-based cancer registry system; ICD-10: International Classification of Diseases, 10th edition; TNM: TNM Classification of Malignant Tumours system; WHO: World Health Organization}

\section{Acknowledgements}

Authors would like to thank the São Paulo Cancer Centre Foundation (FOSP) for data availability.

\section{Funding}

This study was performed during the tenure of the research funding of the "Fundação de Amparo à Pesquisa do Estado de São Paulo (FAPESP)" registered under number 2017/21908-1. The funding is on-going and is exclusively used to support research activities with no influence on the design and collection, analysis and interpretation of data and in writing the reports.

\section{Availability of data and materials}

The datasets analysed during the current study are available in "Download de Arquivos RHC FOSP" http://www.fosp.saude.sp.gov.br/publicacoes/ downloadarquivos.

\section{Disclaimer}

Where authors are identified as personnel of the International Agency for Research on Cancer / World Health Organization, the authors alone are responsible for the views expressed in this article and they do not necessarily represent the decisions, policy or views of the International Agency for Research on Cancer / World Health Organization.

\section{Authors' contributions}

DBV and FSS contributed to conception and design, acquisition, analysis and interpretation of data. CCF, JYS, PB and LZCZ were involved in drafting the manuscript and revising it critically for important intellectual content. All authors approved the final version to be published and agreed to be accountable for all aspects of the work in ensuring that questions related to the accuracy or integrity of any part of the work are appropriately investigated and resolved.

Ethics approval and consent to participate

No permission was needed to access the data used in the study (data was publicly available).

This study was approved by the Ethics Committee of the State University of Campinas under number CAAE 89399018.2.0000.5404. The Committee waived the need for consent.

Consent for publication Not applicable. 


\section{Competing interests}

The authors declare that they have no competing interests.

\section{Publisher's Note}

Springer Nature remains neutral with regard to jurisdictional claims in published maps and institutional affiliations.

\section{Author details}

'Obstetrics and Gynecology Department, School of Medical Sciences of Unicamp, Rua Alexander Fleming 101, Campinas 13083-790, Brazil. ${ }^{2}$ Medicine School of PUC-Campinas, Av. John Boyd Dunlop s/n, Campinas 13060-904, Brazil. ${ }^{3}$ International Agency for Research on Cancer, 150 Cours Albert Thomas, 69372 Lyon, France.

\section{Received: 7 September 2018 Accepted: 26 April 2019}

\section{Published online: 10 May 2019}

\section{References}

1. Ferlay J, Soerjomataram I, Ervik M, Dikshit R, Eser S, Mathers C, Rebelo M, Parkin DM, Forman D, Bray, F. GLOBOCAN 2012 v1.0, Cancer Incidence and Mortality Worldwide: IARC CancerBase No. 11. 2013. http://globocan.iarc.fr/ Default.aspx. Accessed 9 Dec 2016.

2. International Agency for Research on Cancer. Breast Cancer Screening, IARC Handbooks of Cancer Prevention. 2016.

3. Zuo T, Zeng H, Li H, Liu S, Yang L, Xia C, et al. The influence of stage at diagnosis and molecular subtype on breast cancer patient survival: a hospital-based multi-center study. Chin J Cancer. 2017;36:84.

4. American Cancer Society. Breast Cancer Survival Rates \& Statistics. 2018. https://www.cancer.org/cancer/breast-cancer/understanding-a-breastcancer-diagnosis/breast-cancer-survival-rates.html. Accessed 23 Apr 2018

5. Sopik V, Sun P, Narod SA. Impact of microinvasion on breast cancer mortality in women with ductal carcinoma in situ. Breast Cancer Res Treat 2018;167:787-95.

6. Migowski A, Silva GAE, Dias MBK, Diz MDPE, Sant'Ana DR, Nadanovsky P. Guidelines for early detection of breast cancer in Brazil. II - New national recommendations, main evidence, and controversies. Cad Saude Publica. 2018:34:e00074817.

7. Mendes JDV, Cecilio MAM, Osiano VLRL. Boletim Epidemiológico Paulista. Produção de mamografias no SUS do Estado de São Paulo. 2013.

8. Brasil. Instituto Brasileiro de Geografia e Estatística. Projeção da População das Unidades da Federação por sexo e idade: 2000-2030. http://www.ibge. gov.br/home/estatistica/populacao/projecao_da_populacao/2013/default. shtm. Accessed 28 May 2015

9. Brasil. DATASUS. SISCOLO / SISMAMA. http://datasus.saude.gov.br/sistemase-aplicativos/epidemiologicos/siscolo-sismama. Accessed 3 Aug 2017.

10. Instituto Nacional de Câncer. Estimativas de câncer 2018. http://www1.inca. gov.br/estimativa/2018/. Accessed 12 July 2018.

11. Instituto Nacional de Câncer. Statistics on Cancer in Brazil in 2002. Rev Bras Cancerol 2002:48:175-179.

12. Brasil. Agência Nacional de Saúde Suplementar. ANS Tabnet - Informações em Saúde Suplementar: Beneficiários. http://www.ans.gov.br/anstabnet/cgibin/dh?dados/tabnet_br.def. Accessed 12 Jun 2015.

13. Brasil. Instituto Nacional de Câncer. In: Registro hospitalar de câncer; 2017. https://irhc.inca.gov.br/RHCNet/.

14. Bleyer A, Welch HG. Effect of three decades of screening mammography on breast-cancer incidence. N Engl J Med. 2012;367:1998-2005.

15. Welch HG, Prorok PC, O'Malley AJ, Kramer BS. Breast-Cancer Tumor Size, Overdiagnosis, and Mammography Screening Effectiveness. N Engl J Med. 2016:375:1438-47.

16. World Health Organization. WHO | Breast cancer: prevention and control. WHO. http://www.who.int/cancer/detection/breastcancer/en/. Accessed 23 Apr 2018

17. Yip C-H, Smith RA, Anderson BO, Miller AB, Thomas DB, Ang E-S, et al. Guideline implementation for breast healthcare in low- and middle-income countries: early detection resource allocation. Cancer. 2008;113(8 Suppl): 2244-56.

18. Shulman LN, Willett W, Sievers A, Knaul FM. Breast cancer in developing countries: opportunities for improved survival. J Oncol. 2010;2010:595167.

19. Davidson A, Chia S, Olson R, Nichol A, Speers C, Coldman AJ, et al. Stage, treatment and outcomes for patients with breast cancer in British Columbia in 2002: a population-based cohort study. CMAJ Open. 2013;1:E134-41.
20. Walters S, Maringe C, Butler J, Rachet B, Barrett-Lee P, Bergh J, et al. Breast cancer survival and stage at diagnosis in Australia, Canada, Denmark, Norway, Sweden and the UK, 2000-2007: a population-based study. Br J Cancer. 2013;108:1195-208.

21. Justo N, Wilking N, Jönsson B, Luciani S, Cazap E. A review of breast cancer care and outcomes in Latin America. Oncologist. 2013;18:248-56.

22. Perry et al., editors. European guidelines for quality assurance in breast cancer screening and diagnosis. Fourth edition. 2006.

23. Independent UK Panel on Breast Cancer Screening. The benefits and harms of breast cancer screening: an independent review. Lancet Lond Engl. 2012; 380:1778-86.

24. Fracheboud J, Otto SJ, van Dijck J A. a. M, Broeders MJM, Verbeek ALM, de Koning $\mathrm{HJ}$, et al. Decreased rates of advanced breast cancer due to mammography screening in The Netherlands. Br J Cancer 2004;91:861-867.

25. Hofvind S, Lee Cl, Elmore JG. Stage-specific breast cancer incidence rates among participants and non-participants of a population-based mammographic screening program. Breast Cancer Res Treat. 2012;135:291-

26. Foca F, Mancini S, Bucchi L, Puliti D, Zappa M, Naldoni C, et al. Decreasing incidence of late-stage breast cancer after the introduction of organized mammography screening in Italy. Cancer. 2013;119:2022-8.

27. Simbrich A, Wellmann I, Heidrich J, Heidinger O, Hense H-W. Trends in advanced breast cancer incidence rates after implementation of a mammography screening program in a German population. Cancer Epidemiol. 2016;44:44-51.

28. Basu P, Ponti A, Anttila A, Ronco G, Senore C, Vale DB, et al. Status of implementation and organization of cancer screening in the European Union Member States - summary results from the second European screening report. Int J Cancer. 2017.

29. Instituto Nacional de Câncer. Registro de Câncer de Base Populacional. https://www.inca.gov.br/BasePoplncidencias/Home.action. Accessed 17 June 2018.

30. American Cancer Society. Breast Cancer Facts \& Figures, vol. 2018; 2017 2018

31. Mexico. Secretaria de Salud. Perfil Epidemiologico de los Tumores Malignos en Mexico. Mexico, Distrito Federal.; 2011.
Ready to submit your research? Choose BMC and benefit from:

- fast, convenient online submission

- thorough peer review by experienced researchers in your field

- rapid publication on acceptance

- support for research data, including large and complex data types

- gold Open Access which fosters wider collaboration and increased citations

- maximum visibility for your research: over $100 \mathrm{M}$ website views per year

At $\mathrm{BMC}$, research is always in progress.

Learn more biomedcentral.com/submissions 